NOTE: This is an Accepted Manuscript of an article published by Taylor \& Francis in

"Contemporary Politics", available online:

http://dx.doi.org/10.1080/13569775.2016.1210875

\title{
Citation:
}

Hooghe, M., Marien, S., \& Oser, J. (2017). Great expectations: the effect of democratic ideals on political trust in European democracies. Contemporary Politics, 23(2), 214-230.

\section{Great Expectations \\ The Effect of Democratic Ideals on Political Trust in European Democracies}

\begin{abstract}
While in the older literature, low levels of political trust were routinely interpreted as a lack of support for democracy, more recently authors have claimed that the value pattern of critical citizens is a hallmark for a mature and stable democratic system. In this paper we assess the empirical validity of this claim, by relying on the relative deprivation literature highlighting the relation between expectation and frustration. The 2012 wave of the European Social Survey included an extensive battery measuring democratic ideals, and using latent class analysis we identify a group with high ideals on how a democracy should function. Multilevel regression analysis shows that strong democratic ideals are associated with lower levels of political trust, and most strongly so in countries with low quality of government. We close with observations on how rising democratic ideals could be a cause for the occurrence of a new group of 'critical citizens'.
\end{abstract}

Keywords: political trust, democracy, civic culture, European Social Survey, latent class analysis; relative deprivation 


\section{Introduction}

Political trust, almost by definition, remains an elusive concept. It has been argued repeatedly that in most cases citizens lack the necessary knowledge to ascertain whether politicians really are trustworthy (Hardin, 1999). Nevertheless, research has repeatedly shown that political trust functions as an important resource for the stability of democratic political systems (Easton, 1975). Furthermore, we know that political trust is important for social stability as it is associated with a stronger commitment to law compliance (Marien \& Hooghe, 2011).

However, authors working within the 'critical citizens' tradition have argued that conceptualizing contemporary political culture requires attention to other attitudes in addition to political trust (Dalton \& Welzel, 2014; Norris, 1999). As Dalton and Shin $(2014,103)$ have stated quite strongly: 'In most highly consolidated democracies, confidence in central democratic institutions has been falling in recent decades. Political criticism is the spirit of the contemporary age'. Their argument is that while political trust was perhaps an essential component of the allegiant political culture as it was described in the seminal work of Almond and Verba (1963), it no longer occupies this central place for a new generation of 'assertive citizens'. From this 'assertive citizens' perspective, political criticism is seen as a defining value of contemporary political culture. These assertive citizens are strong supporters of basic democratic values, but simultaneously they adopt a highly critical and vigilant outlook toward politicians and political institutions (Rosanvallon, 2006).

In this paper, we present an alternative test for this 'assertive citizen' argument (Dalton \& Welzel, 2014). While in the older literature, political distrust was often interpreted as an indicator for political alienation, authors like Norris (1999) have argued that distrust could be an indicator for a healthy and thriving democratic political culture. If this argument is correct, we should be able to observe that those who expect most from democracy, in practice will be disappointed if politicians do not manage to live up to these high ideals. In this view, distrust is rather an indication of the fact that normative ideals toward democracy have become more exigent. These kinds of high expectations may moderate the view on the functioning of democracy, which could help us to explain differential dynamics with regard to political trust (Hakhverdian \& Mayne, 2012). Earlier research indeed shows that evaluations of the political system are to a large extent dependent on the pre-existing attitudes and expectations of citizens 
(Anderson \& Singer, 2008; Jakobsen, 2010). While evalutions of the political system clearly are important, the role of expectations thus far has remained neglected in empirical research. Self-evidently, it is always difficult to measure in a comprehensive manner what citizens exactly expect from democracy (Bengtsson \& Christensen, 2016; Flanagan et al., 2005). The 2012 wave of the European Social Survey, however, included an extensive battery that asks respondents about the importance of different features of democracy. This innovative battery allows us to comprehensively investigate the democratic ideals of European citizens in terms of what is important to them in order to attain a full democracy. This paper investigates the impact these ideals have on levels of political trust.

In this paper we first review the literature on democratic ideals and political trust, before we present the data and methods. We investigate what kind of ideals citizens have with regard to democracy, and subsequently how these ideals are related to the level of political trust. We close with some observations about what a relative deprivation perspective could imply for the future study of (trends in) political trust levels.

\section{What Do Citizens Want from Democracy?}

In most of the literature, political trust is seen as the single most important form of diffuse support for democratic political systems (Easton, 1975). If citizens trust the main institutions of the political system, this implies that on average they consider the functioning of the political system to be legitimate and democratic. Political trust indeed can be defined 'as the degree to which people perceive that government is producing outcomes consistent with their expectations' (Hetherington, 2005, 9). Within this framework, political trust can only be considered as a positive phenomenon that is essential for democratic stability (Zmerli \& Hooghe, 2011). Theoretically, political trust is a crucial component of the allegiant political culture that is central in the work of Gabriel Almond and Sidney Verba (1963). In the United States, a downward trend with regard to political trust has been identified (Pharr \& Putnam, 2000), but it has to be noted that this trend is not observed in European countries. Within the theoretical framework of the 'Civic Culture' literature, low levels of political trust can only be seen as a problematic phenomenon (Bovens \& Wille, 2011; Hooghe \& Dassonneville, forthcoming). 
An alternative interpretation for this phenomenon is presented in the work on 'critical citizens' (Norris, 1999). In this line of the literature, it is stated that citizens are increasingly critical toward the functioning of the political system, but that this should not be seen as a reason for concern. On the contrary, the presence of more critical citizens is seen as an indicator for the maturity of democratic political systems. While this line of reasoning has been highly influential in the literature, empirical investigations of this phenomenon have been largely descriptive in nature, and have lacked a discussion of potential variance in different contexts. For example, there is no hint of cross-national distinction in Welzel and Dalton's $(2014,287)$ observation that 'contemporary publics more often combine a deep normative commitment to democratic ideals with dissatisfaction on how governments fulfill these ideals'. The goal of this article, therefore, is not to explain the occurrence or the prevalence of these ideals, but rather their effect on political trust in diverse contemporary contexts.

In the current stage of research, we do not know why exactly citizens have become more critical in their evaluation of the political system. In fact, there are even some reasons to expect a more positive attitude. First, a rather straightforward assumption could be that rising average education levels in Western societies should be associated with a similar trend in levels of political trust. After all, we know that on an individual level, there is a strong positive correlation between education level, and political sophistication and political trust (Hooghe, Dassonneville \& Marien, 2015; Persson, 2014). As average education levels continue to increase in most European societies, one would therefore expect that levels of political trust would increase in a similar way. It remains a challenge to explain why political trust would decline in an era when average education levels are still rising after the rapid expansion of the education system in the second half of the $20^{\text {th }}$ century.

A second problem is that efforts to develop an objective quality of government standard, do not offer any indication at all that the quality of governance would actually have declined in Western societies. A downward trend in governmental performance would have served as an obvious reason for a decline in political trust, but apparently such a decline does not occur. It can indeed be assumed that when citizens are confronted with a sub-standard performance of institutions, they will be inclined to lose trust in the political system altogether (De Vroome, Hooghe \& Marien, 2013; Rothstein \& Stolle, 2008). Seyd (2015) furthermore has shown that trust is shaped primarily by an evaluation of how public officials perform. There is no reason at all, however, to assume that the quality of democratic governance would have declined in 
Europe (Rothstein, 2011), and therefore government performance is an unlikely candidate to explain any downward trend in political trust. The trends with regard to average education level and with regard to the quality of government, therefore, do not offer any explanation for the occurrence of a more critical and distrusting attitude among the citizens of European societies.

Some authors, however, have emphasized the claim that expressions of trust are largely dependent on normative expectations (Norris, 1999). The literature on relative deprivation suggests that discontent might not just be the result of negative evaluations, but also of rising expectations (Abeles, 1976; Gurr, 1970). Within this line of the literature, the main argument is that frustration cannot be explained by just invoking objective conditions, but is a result of the gap between expectations or norms, and the perceived reality. Rising expectations, therefore, will lead to frustration and dissatisfaction, if the quality of services does not rise as strongly as expectations do. Building on this literature, we argue that efforts to explain levels of political trust should investigate citizens' subjective evaluation of government functioning, in addition to their democratic ideals.

To put it differently: feelings of deprivation or frustration should not just be seen as a reaction to objective conditions, but they arise out of the distance between expectations and experiences. If the quality of government remains constant, but expectations are rising, this will result in an increasing sentiment of deprivation. If we want to explain trends in political trust and test the critical citizens argument, the literature on relative deprivation implies that we also have to take into account the normative ideals citizens have toward the political system (Smith et al., 2012). Our argument, therefore, is that ideals with regard to democracy should be a central focus of research on democratic legitimacy. Moreover, the relation between democratic ideals and political trust is likely to be influenced by the quality of the performance of the political system and we know from previous research that evaluations are indeed crucial in this regard (Seyd, 2015). We could expect that especially when the distance between expectations and performance is large, frustrations arise leading to lower levels of political trust. Our main hypothesis in this analysis, therefore, is that exigent democratic ideals among citizens will be associated with low levels of political trust. Furthermore, in addition to our expectation that democratic ideals will have a direct effect on political trust, there are also good reasons to expect a moderating effect. Those who start with high expectations, are more likely to be disappointed when they perceive the quality of democratic governance to be low. Following the logic developed by Hakhverdian and Mayne (2012), we hypothesize therefore the occurrence of a 
cross-level interaction effect, where respondents with the highest expectations react most strongly to the quality of government.

\section{Data and Methods}

The European Social Survey in 2012 provides a unique opportunity to investigate citizens' democratic ideals. Data were collected between 2012 and 2013 by means of uniform face-toface interviews among representative samples of the population of 29 European countries (ESS Round 6, 2012). In an extended battery of questions, respondents were presented a variety of aspects of democracy, and were asked to give a score for the importance of each item ('How important do you think it is for democracy in general that...'). The items included in this battery cover diverse aspects of democratic functioning ranging from free and fair elections and the protection of minority rights to protecting citizens against poverty (Ferrín \& Kriesi, 2016).

When we review the mean values of the items in this battery, a first striking finding is that respondents tend to consider almost all elements as very important (Table 1). The rule of law (expressed by the item: 'The courts treat everyone the same'), however, is clearly considered as the most important hallmark of a democratic political system with a score of 9.22 on the 0 to 10 scale. For the population of Europe, this democratic standard is clearly almost sacrosanct in status. Free and fair elections obtain an almost equally high score (8.96). It is clear, however, that protecting citizens from poverty, also receives a very high score (8.68), indicating that poverty reduction is also seen as an important responsibility for a democratic political system. Finally the lowest average score is found for the item that political parties should offer clear alternatives with regard to policy orientations.

\section{[Table 1 about here]}

If we want to determine how these democratic ideals have an impact on political trust, it is important to try to understand the internal structure of these normative concepts. To understand citizens' conceptions of democratic ideals, the absolute scores on these items are less informative than the way individual citizens combine various items into coherent sets of value priorities. In order to identify whether citizens hold distinctive democratic ideals in terms of the elements of democracy they consider most important, we performed a latent class analysis 
(LCA) that allows us to identify groups of respondents that are characterized by a similar combination of items in this battery. The main advantage of LCA is that it allows for the identification of latent structures that are not based on the separate items, but rather on how individuals responding in the survey combine those items in distinctive patterns. Therefore we can identify distinct groups of respondents who emphasize different combinations of items as priorities with regard to what is important for a democracy. In other words, LCA allows us to identify groups of people who have distinctly different conceptions of what an ideal democracy looks like. This combination of items leads to specific democratic ideals. In contrast to traditional cluster analysis, LCA allows the researcher to determine the optimal number of clusters to be distinguished based on objective goodness of fit criteria, while for cluster analysis this often amounts to a rather arbitrary decision (Vermunt, 2008). Since LCA is an actorcentered analytical approach, it allows us to identify respondents who emphasize specific items among the 11-indicator battery in terms of what they consider to be most important for democracy. This approach is therefore preferable for answering our research questions in comparison to the more familiar technique of factor analysis, which identifies latent dimensions of the variables without identifying overall patterns and typologies of individual responses.

Latent class analysis identifies five distinct groups of respondents (see online appendix for documentation of model selection). This five group solution offers the best fit between model and available data. The LCA findings point to distinctive democratic ideals held by five different groups of citizens. First, the latent class labeled 'high ideals', which includes $23 \%$ of the respondents, identifies a group of citizens who deemed all of the elements of democracy investigated in the survey to be highly important. This group of respondents gives the maximum score to almost all of the items, without any further distinction. Conversely, the group labeled 'low ideals', which includes $10 \%$ of the respondents, attributed relatively low importance to all of the democracy indicators. An additional group labelled 'medium ideals' (31\% of the population) consistently attributed moderate importance to all indicators. These findings show that almost two-thirds of the respondents $(64 \%)$ do not attribute special importance to specific elements of democracy, but rather give all of them similar priority.

The two additional latent classes identify individuals who have two contrasting normative conceptions of what is important for democracy. The democratic ideal labeled as 'social rights' that is held by $20 \%$ of the respondents places relatively high importance on social and economic elements such as democratic values of economic equality (reduction of income inequality and 
protection from poverty) and governmental accountability (government explains its decisions and is held accountable in elections). Simultaneously, however, this group does not pay all that much attention to classic political rights, such as the presence of free media. In contrast, the ideal labeled 'political rights' that is held by $16 \%$ of the respondents places relative emphasis on the importance of a free and competitive electoral process, free media, and the protection of minority rights. This group, on the other hand, scores low on classic social rights, such as the objective of poverty reduction. The results of the analysis, therefore clearly show that, despite the fact that all items seem to receive rather high scores, we can indeed empirically distinguish five groups that hold different opinions on what is considered to be important in democracy. This allows for sufficient variation to use these ideals of democracy as our independent variable in the analysis. Since in Figure 1 the democracy indicators are ordered on the $\mathrm{x}$-axis from highest to lowest means in the general population, the contrasting emphases of these democratic ideals is visually clear in the crossing of the connective lines. Especially the political rights and the social rights group are characterized by sometimes opposing scores on specific items.

[Figure 1 about here]

The analysis suggests that this five group solution for the democratic ideals scale is crossculturally equivalent, implying that these distinctions hold well in the countries that have participated in the European Social Survey. We can observe, however, strong differences between countries with regard to the prevalence of these ideals. The group with very high expectations with regard to democracy is most prevalent in recent democracies like Kosovo or Albania. It is less prevalent in very established democracies like Belgium, the Netherlands and Finland. Social rights are emphasized in Slovenia and Albania, while political rights are strongest in Denmark, Iceland and Sweden. Yet it is important to note that cross-cultural equivalence testing indicated that these groups can be identified in every country under study (See online appendix).

[Table 2 about here]

\section{The Relation with Political Trust}


After having defined groups of citizens with distinct democratic ideals, we now move on to address our main research question: how are these ideals related to political trust? The European Social Survey included a battery of institutions, and respondents were invited to indicate their level of trust in each of these institutions. Given our focus on national political systems, we included in our analysis the five national political institutions available in the survey: Parliament, the legal system, police, political parties and politicians. The trust score on these five items was added in a sum scale to arrive at a political trust scale. ${ }^{1}$ A first overview of the means scores on the political trust scale (Table 3) already suggests that there are indeed marked differences across groups $(\mathrm{F}=390.76, \mathrm{p}<0.001)$. The highest trust score can be found among the respondents who belong to the political rights class. Those who claim that a democracy should focus most strongly on protecting political rights also seem to have the highest trust levels. The mean scores suggest that we find the lowest level of political trust among the respondents who consider all aspects of democracy to be highly important. This first analysis, therefore, seems to suggest that holding very high ideals toward democracy indeed might be associated with low levels of trust in political institutions.

[Table 3 about here]

Following this first exploration of the data, we now proceed to a full multivariate and multilevel analysis to explain levels of political trust. First, we include of course the five groups of democratic ideals that we have identified, with an assignment to the specific groups as our main independent variable. The 'medium ideals' groups serves as the reference category. Furthermore, we include control variables that are routinely included in the analysis of critical citizenship in contemporary democracies (Dalton \& Welzel, 2014). Most of the research suggests that higher education levels are associated with higher levels of political trust, while trust levels also tend to be higher among older age groups. We also control for the selfplacement on an ideological left-right scale, since right-wing voters tend to have higher levels of political trust (Hooghe, Marien \& De Vroome, 2012).

At the country level, it first has to be noted that the number of observations is rather limited and country-level characteristics are generally highly correlated, so the few country level variables that we have available will be introduced one by one in the analysis (Table 4). A first control 
variable is GDP per capita, as it can be assumed that trust is higher in more affluent societies (Armingeon \& Ceka, 2014). A second routinely used control variable includes the difference between well-established and newer democracies. We based this variable on information retrieved from the Polity IV dataset. We considered those countries that obtained a score of minimum 8 during the past thirty years to be established democracies. In addition, we also control for countries that are not democratic or have begun to function democratically only within the past ten years (score lower than 8) and labeled them 'weak democracies' (i.e., Albania, Kosovo, Russia and Ukraine). ${ }^{2}$ In recent years, various scholars have defended the claim that objective and reliable measurements for the quality of government are available and empirically valid (Charron \& Lapuente, 2013; Rothstein, 2011). If political trust is in some way related to the quality of government, we should observe a positive relation between the two indicators. Here we use the Good Governance indicator as developed by the World Bank. However, we do not expect a simple direct relation between good governance indicators and levels of political trust. The relative deprivation perspective suggests that citizens will be especially frustrated if their high level of expectations is not matched by equally high levels of performance. Therefore, we estimate cross-level interaction effects between governance quality in a country and respondents' democratic ideals on their levels of political trust. ${ }^{3}$ Given the nested structure of the data, we use a multilevel regression and subsequently estimate random intercept models, random slope models and random slope models that include cross-level interaction effects. $^{4}$

In a first model (Table 4) we include only the individual level variables, and the results are striking. ${ }^{5}$ The group with high democratic ideals indeed has significantly lower levels of political trust, and the relation is substantial. Those stressing social rights also are characterized by lower levels of political trust, while we find the opposite effects for respondents who stress political rights. The control variables generally confirm established findings in the literature. We can observe a strong education effect, with the highest trust levels among the group with the highest educational degree. Those who identify themselves on the right side of the political spectrum, also have significantly higher trust levels. In Model II (Table 4) we first introduce GDP per capita as a control variable on the country level. The association is positive and significant, indicating that political trust levels are higher in richer societies. Including this variable in the model, however, does not change the individual level effects. In models III, IV and $\mathrm{V}$ we find a strong positive relation with the presence of stable democracy and good governance indicators. This confirms the notion that there is at least some relation between 
political trust and good governance, although the direction of causality might be disputed. It can be noted, however, that our results with regard to the relation between democratic ideals and political trust do not seem to be affected by different country level indicators. ${ }^{6}$ In all models, it is obvious that the lowest trust levels can be seen among the group that has high expectations. Furthermore, an additional analysis shows that this high expectations group is characterized by an on average high level of education and political interest. Hence, it is clear that high ideals are clearly not the result of a lack of political sophistication. Finally, in Model VI, we add interact terms to the models to investigate whether the relationship between expectations and political trust is influenced by performance. The slopes are found to vary across the countries and most of the interaction terms prove to be significant, suggesting that the relation between expectations and performance indeed is important in this regard. As hypothesized, those with the highest level of expectations indeed react most strongly to the quality of government. A somewhat counter-intuitive finding is that the group with lower expectations stands out, as it reacts negatively to higher levels of democratic governance. This might indicate some form of negativity bias, that appears to be present within this group (Soroka, 2014), but obviously this relation is in need for further investigation.

[Table 4 about here]

To interpret the nature of these interaction effects, marginal effects were estimated. For the sake of clarity, we present the groups two by two in Figures 2 and 3. Each time the group with medium ideals serves as reference category. In Figure 2 the marginal effects of 'low ideals' and 'high ideals' on political trust are plotted according to the level of performance of the national political institutions. The figure reveals that high ideals are associated with lower levels of political trust in all countries except those receiving the highest scores on the good governance index (Scandinavian countries, the Netherlands, Switzerland). This means that the negative relation between respondents' high democratic expectations and their levels of political trust is stronger in countries that have low governance indicators. Only in countries where institutions function extremely well, high expectations do not have a negative effect on trust levels. The interaction effect is clear: in countries that do not perform well, citizens with high democratic expectations have very low levels of political trust. 
In Figure 3 it is shown that an emphasis on social rights is associated with low levels of political trust in most countries and the association proves to be rather constant across all countries. ${ }^{7}$ An emphasis on political rights is related to lower levels of political trust in countries that score low on the good governance index but with higher levels of political trust in countries that score high on the good governance index. Here too, the interaction effect is in line with the relative deprivation logic: especially in low-performance countries, specific expectations are associated with low levels of political trust. In sum, the interaction effects confirm that the group with high democratic ideals has significantly lower levels of political trust, especially in countries that score low on good governance indicators and the effect is quite substantial. ${ }^{8}$

[Figure 2 about here]

[Figure 3 about here]

\section{Discussion}

In most of the literature, there is a pressing concern about trends with regard to levels of political trust in established democracies. Although the available literature does not document clear downward trends, it can be noted that in some countries there is concern about an alleged decline of democratic legitimacy (Thomassen \& van Ham, 2014). The debate however concentrates on the normative implications of this finding. Dalton and Shin $(2014,106)$ note quite optimistically: 'In most highly consolidated democracies, confidence in central democratic institutions has been falling in recent decades. Political criticism is the spirit of the contemporary age.'

A first conclusion of our study is that many of the classic findings still hold in the current age. Levels of political trust are significantly higher among highly educated citizens and in stable democracies. Our findings also allow us to qualify some of the misgivings about low levels of political trust. We find lower levels of political trust among citizens who have very high ideals about what a democratic society should look like, and this points to an important lacuna in the current literature on political trust. Political trust is routinely portrayed as a response to the functioning of the political system, or as a reaction to specific experiences with members of these institutions (Seyd, 2015). The relation, however, is more complex, as the evaluation is also related to expectations about the importance of different elements of democracy. It has to be remembered in this regard that frustration only occurs when experiences remain below the 
level of expectations. In a distinct analysis we also tested the subjective evaluation of the respondents as an independent factor, and these findings indicated that expectations have a strong autonomous effect in this regard, without however invalidating our findings. The fact that political trust levels are lowest among the group that expects most from democratic governance is a clear indicator that it is important to take expectations into account. Theoretically this implies that we should not expect general and uniform reactions to the quality of government, but that, depending on their pre-existing expectations, different segments of the population will react differently to what might be exactly the same circumstances. The interaction patterns that are illustrated in Figure 2, also point to a clear frustration pattern: a combination of high ideals and low performance is associated with plummeting trust levels. On the other hand, exacting ideals do not seem to have any effect at all on trust levels in countries that outperform the others with regard to government functioning. In contrast to what the traditional 'civic culture' literature assumed we do not find the lowest levels of political trust among those who do not expect a lot from democracy, but rather among citizens who are most exigent.

This also allows us to solve an apparent puzzle: Klingemann (2014) rather directly assumes that assertive citizens will also be 'dissatisfied democrats'. As long as we see political trust as purely the result of some kind of evaluation process, there is no apparent logic in this claim. Even highly critical citizens could be satisfied, if they live in a country that receives high scores on the good governance indicators (like is the case in the Scandinavian countries). If citizens in these countries make an objective assessment, they should have rather high levels of political trust. The current analysis, however, reminds us that evaluations tend to be based on a normative standard or on an expectation pattern. In a vast majority of countries, adhering to very high democratic ideals almost automatically will be associated with some disappointment in the evaluation of how democracy actually functions. This observation might help us to explain the Klingemann puzzle: critical citizens may become dissatisfied democrats for the simple reason that their expectations are so high and only a few countries succeed in matching those expectations.

It is equally important, however, to distinguish between different kinds of ideals: while an emphasis on social rights was negatively related to political trust, the opposite was true for an emphasis on political rights. Indeed, in almost all of the countries participating in the survey, basic political rights are controlled by supranational organizations like the Council of Europe, 
so we can assume that these rights are guaranteed in the countries that we investigate. Especially in the current climate of austerity and crisis, there is no similar safeguard for social rights. It seems plausible that disappointment about the incapacity of the state apparatus to combat poverty is linked to this negative assessment. This is a highly relevant finding given the current trend toward a retrenchment of the welfare state in many European countries. To the extent that these policies lead to increasing poverty and exclusion, it can be expected that this will lead to lower levels of political trust, especially among those citizens who consider it as essential duty for a democratic political system to reduce poverty in society (Zmerli \& Castillo, 2015).

The findings in this article show that it is highly relevant for future discussions on trends in political trust to take into account the ideals citizens have with regard to democracy. Levels of political trust should not just be seen as a form of evaluation of the function of the political system since the norms that are used to make this assessment are equally important. As has been noted: the 'democratic ideals' battery in ESS 2012 was unique, so we cannot assess time trends with regard to these expectations. It seems reasonable to assume, however, that expectations toward democracy have become higher as a result of higher average education levels. The 'critical citizens' literature would also lead to the assumption that expectations with regard to democracy would have become higher in recent decades due to general shifts in norms, as citizens now stress more strongly the importance of self-expressive values and general principles of individual freedom. It is not possible given the data at hand to assess whether political systems can live up to consistently increasing democratic expectations. A challenge for future research, therefore, is to investigate whether and if so, how political systems are confronting an uphill struggle as they attempt to address an ever expanding set of expectations from their citizens. This could even be interpreted as a self-defeating trend: from a normative point of view, it can only be applauded that citizens expect a lot from democracy. If these high expectations, however, entail an almost inevitable disappointment with the actual functioning of the system, it can be questioned whether these critical citizens will actually help to achieve the high democratic norms they aspire to.

\section{References}

Abeles, R. (1976). Relative Deprivation, Rising Expectations, and Black Militancy. Journal of Social Issues, 32(2), 119-137.

Agresti, A. (2007). An Introduction to Categorical Data Analysis (2nd ed.). Hoboken: Wiley. 
Almond, G. \& S. Verba (1963). The Civic Culture. Princeton: Princeton University Press.

Anderson, C. \& Singer, M. (2008). The Sensitive Left and the Impervious Right. Multilevel Models and the Politics of Inequality, Ideology, and Legitimacy in Europe. Comparative Political Studies, 41(4-5), 564-599.

Armingeon, K. \& Ceka, B. (2014). The loss of trust in the European Union during the great recession since 2007: The role of heuristics from the national political system. European Union Politics, 15(1), 82-107.

Bengtsson, Å. \& Christensen, H.S. (2016). Ideals and Actions: Do Citizens’ Patterns of Political Participation Correspond to their Conceptions of Democracy? Government and Opposition, 51(2), 234-260.

Bovens, M. \& Wille, A. (2011). Falling or Fluctuating Trust Levels? The Case of the Netherlands, pp. 47-66 is S. Zmerli \& M. Hooghe (eds.), Political Trust. Why Context Matters. Colchester: ECPR Press.

Charron, N. \& Lapuente, V. (2013). Why Do Some Regions in Europe Have a Higher Quality of Government? Journal of Politics, 75(3), 567-582.

Dalton, R. \& Shin, D.C. (2014). Reassessing the Civic Culture model, pp. 91-115 in R. Dalton \& C. Welzel (eds.), The Civic Culture Transformed. Cambridge: Cambridge University Press.

Dalton, R. \& Welzel, C. (eds., 2014). The Civic Culture Revisited. From Allegiant to Assertive Citizens. Cambridge: Cambridge University Press.

De Vroome, T., Hooghe, M. \& Marien, S. (2013). The origins of generalized and political trust among immigrant minorities and the majority population in the Netherlands. European Sociological Review, 29(6), 1336-1350.

Easton, D. (1975). A Re-assessment of the Concept of Political Support. British Journal of Political Science, 5(4), 435-457. 
ESS Round 6: European Social Survey Round 6 Data (2012). Data file edition 2.1. Norwegian Social Science Data Services, Norway - Data Archive and distributor of ESS data.

Ferrín, M. \& Kriesi, H. (eds., 2016). How Europeans View and Evaluate Democracy. Oxford: Oxford University Press.

Flanagan, C., Gallay, L., Gill, S., Gallay, E. \& Nti, N. (2005). What Does Democracy Mean? Correlates of Adolescents' Views. Journal of Adolescent Research, 20(2): 193-218.

Gurr, T. R. (1970). Why Men Rebel. Princeton: Princeton University Press.

Hakhverdian, A. \& Mayne, Q. (2012). Institutional Trust, Education, and Corruption. A Micro-Macro Interactive Approach. Journal of Politics, 74(3), 739-750.

Hardin, R. (1999). Do We Want Trust in Government?, pp. 22-41 in Mark Warren (ed.), Democracy and Trust. Cambridge: Cambridge University Press.

Hetherington, M. J. (2005). Why Trust Matters: Declining Political Trust and the Demise of American Liberalism. Princeton: Princeton University Press.

Hooghe, M., \& Dassonneville, R. (forthcoming). A Spiral of Distrust: A Panel Study on the Relation between Political Distrust and Protest Voting in Belgium. Government and Opposition, in press.

Hooghe, M., Dassonneville, R., \& Marien, S. (2015). The Impact of Education on the Development of Political Trust. Results from a Five-Year Panel Study among Late Adolescents and Young Adults in Belgium. Political Studies, 63(1), 123-141.

Hooghe, M., Marien, S., \& De Vroome, T. (2012). The cognitive basis of trust. The relation between education, cognitive ability, and generalized and political trust. Intelligence, 40(6), 604-613. 
Jakobsen, T. (2010). Public versus Private: The Conditional Effect of State Policy and Institutional Trust on Mass Opinion. European Sociological Review, 26(3), 307-318.

Kankaraš, M., Moors, G., \& Vermunt, J. K. (2010). Testing for measurement invariance with latent class analysis. In E. Davidov, P. Schmidt \& J. Billiet (Eds.), Cross-Cultural Analysis: Methods and Applications (pp. 359-384). New York: Routledge.

Kankaraš, M., \& Vermunt, J. K. (2014). Simultaneous latent class analysis across groups. In A. C. Michalos (Ed.), Encyclopedia of Quality of Life and Well-Being Research. Heidelberg: Springer.

Klingemann, H.-D. (2014). Dissatisfied Democrats: Democratic Maturation in Old and New Democracies, pp. 116-157 in R. Dalton \& C. Welzel (eds.), The Civic Culture Transformed. Cambridge: Cambridge University Press.

Magidson, J., \& Vermunt, J.K. (2004). Latent class models. In D. Kaplan (Ed.), The Sage handbook of quantitative methodology for the social sciences (pp. 175-198). London: Sage.

Marien, S. (2011). Measuring Political Trust Across Time and Space, pp. 13-46 in S. Zmerli \& M. Hooghe (eds.), Political Trust. Why Context Matters. Colchester: ECPR Press.

Marien, S. \& Hooghe, M. (2011). Does political trust matter? An empirical investigation into the relation between political trust and support for law compliance. European Journal of Political Research, 50(2), 267-291.

Norris, P. (ed., 1999). Critical Citizens. Oxford: Oxford University Press.

Persson, M. (2014). Testing the relationship between education and political participation using the 1970 British cohort study. Political Behavior, 36(4), 877-897.

Pharr, S. \& Putnam, R. (eds., 2000). Disaffected Democracies. What's Troubling the Trilateral Countries? Princeton: Princeton University Press.

Rosanvallon, P. (2006). La contre-démocratie. Paris : du Seuil. 
Rothstein, B. (2011). The Quality of Government. Corruption, Social Trust and Inequality in International Perspective. Chicago: University of Chicago Press.

Rothstein, B. \& Stolle, D. (2008). The State and Social Capital: An Institutional Theory of Generalized Trust. Comparative Politics, 40(4), 441-459.

Seyd, B. (2015). How Do Citizens Evaluate Public Officials? The Role of Performance and Expectations on Political Trust. Political Studies, 63, 73-90.

Smith, H., Pettigrew, T., Pippin, G., \& Bialosiewicz, S. (2012). Relative Deprivation: A Theoretical and Meta-Analytic Review. Personality and Social Psychology Review, 16(3), 203-232.

Soroka, S. (2014). Negativity in Democratic Politics. Causes and Consequences. Cambridge: Cambridge University Press.

Thomassen, J. \& C. van Ham (2014). Failing Political Representation or a Change in Kind? Models of Representation and Empirical Trends in Europe. West European Politics, 37(2), 400-419.

Vermunt, J. (2008). Latent Class and Finite Mixture Models for Multilevel Data Sets. Statistical Methods in Medical Research, 17(1), 33-51.

Welzel, C., \& Dalton, R. (2014). From allegiant to assertive citizens. In R. Dalton \& C. Welzel (Eds.), The civic culture transformed: From allegiant to assertive citizens (pp. 282306). Cambridge: Cambridge University Press.

Zmerli, S. \& Castillo, J.C. (2015). Income inequality, distributive fairness and political trust in Latin America. Social Science Research, 52(1), 179-192.

Zmerli, S. \& Hooghe, M. (eds., 2011). Political Trust: Why Context Matters. Colchester: ECPR Press. 
Table 1. Scores on 'Democratic Ideals' Battery

\begin{tabular}{llll} 
Description & Abbreviation & Var. name & Mean \\
\hline The courts treat everyone the same & courts fair & cttresa & 9.22 \\
National elections are free and fair & fair elec. & fairelc & 8.96 \\
The government explains its decisions to voters & govt expl. & gvexpdc & 8.85 \\
The media provide citizens with reliable information to judge the govt. & media info. & meprinf & 8.75 \\
The government protects all citizens against poverty & poverty & gvctzpv & 8.68 \\
Governing parties are punished in elections when they have done a bad job & party acc. & gptpelc & 8.39 \\
The rights of minority groups are protected & minority & rghmgpr & 8.34 \\
Opposition parties are free to criticise the government & opposition & oppcrgv & 8.31 \\
The media are free to criticise the government & free media & medcrgv & 8.26 \\
The government takes measures to reduce differences in income levels & income eq. & grdfinc & 8.24 \\
Different political parties offer clear alternatives to one another & party alter. & dfprtal & 7.99 \\
\hline
\end{tabular}

Notes: European Social Survey, $2012(\mathrm{n}=54,673)$. Prefatory survey question: 'Using this card, please tell me how important you think it is for democracy in general that...'. Responses coded on a 0 to 10 scale where 0 indicates 'not at all important' and 10 indicates 'extremely important'. 
Table 2. Distribution of Democratic Ideals across Countries

\begin{tabular}{llllll}
\hline & $\begin{array}{l}\text { High } \\
\text { ideals }\end{array}$ & $\begin{array}{l}\text { Medium } \\
\text { ideals }\end{array}$ & $\begin{array}{l}\text { Low } \\
\text { ideals }\end{array}$ & $\begin{array}{l}\text { Social } \\
\text { rights }\end{array}$ & $\begin{array}{l}\text { Political } \\
\text { rights }\end{array}$ \\
\hline Albania & 0.45 & 0.15 & 0.01 & 0.31 & 0.08 \\
Belgium & 0.13 & 0.39 & 0.13 & 0.19 & 0.16 \\
Bulgaria & 0.39 & 0.18 & 0.04 & 0.20 & 0.18 \\
Switzerland & 0.13 & 0.39 & 0.07 & 0.19 & 0.22 \\
Cyprus & 0.39 & 0.26 & 0.02 & 0.19 & 0.14 \\
Czech Republic & 0.18 & 0.29 & 0.17 & 0.19 & 0.18 \\
Germany & 0.17 & 0.30 & 0.05 & 0.20 & 0.28 \\
Denmark & 0.16 & 0.33 & 0.03 & 0.17 & 0.31 \\
Estonia & 0.27 & 0.29 & 0.11 & 0.17 & 0.15 \\
Spain & 0.32 & 0.26 & 0.07 & 0.28 & 0.08 \\
Finland & 0.12 & 0.41 & 0.10 & 0.19 & 0.17 \\
France & 0.18 & 0.38 & 0.09 & 0.20 & 0.14 \\
United Kingdom & 0.19 & 0.35 & 0.13 & 0.20 & 0.13 \\
Hungary & 0.38 & 0.22 & 0.13 & 0.16 & 0.12 \\
Ireland & 0.21 & 0.35 & 0.17 & 0.15 & 0.12 \\
Israel & 0.22 & 0.34 & 0.06 & 0.21 & 0.17 \\
Iceland & 0.23 & 0.28 & 0.04 & 0.15 & 0.29 \\
Italy & 0.26 & 0.30 & 0.05 & 0.29 & 0.12 \\
Lithuania & 0.22 & 0.31 & 0.19 & 0.17 & 0.11 \\
Netherlands & 0.10 & 0.43 & 0.15 & 0.13 & 0.19 \\
Norway & 0.17 & 0.34 & 0.04 & 0.17 & 0.27 \\
Poland & 0.27 & 0.26 & 0.04 & 0.26 & 0.17 \\
Portugal & 0.31 & 0.26 & 0.22 & 0.17 & 0.05 \\
Russian Federation & 0.26 & 0.24 & 0.15 & 0.21 & 0.13 \\
Sweden & 0.23 & 0.27 & 0.04 & 0.14 & 0.32 \\
Slovenia & 0.21 & 0.30 & 0.05 & 0.32 & 0.12 \\
Slovakia & 0.16 & 0.36 & 0.20 & 0.16 & 0.12 \\
Ukraine & 0.31 & 0.27 & 0.07 & 0.23 & 0.12 \\
Kosovo & 0.37 & 0.24 & 0.11 & 0.22 & 0.06 \\
TOTAL & 0.23 & 0.31 & 0.10 & 0.20 & 0.16 \\
\hline
\end{tabular}

Notes: European Social Survey, $2012(\mathrm{n}=54,673)$. Distribution of groups across participating countries, as identified in the latent class analysis. 
Table 3. Political Trust Means of Groups

\begin{tabular}{lll} 
& Mean & S.D \\
\hline Political rights group & 4.796 & 2.215 \\
Medium ideals group & 4.460 & 2.072 \\
Low ideals group & 4.061 & 1.914 \\
Social rights group & 3.979 & 2.229 \\
High ideals group & 3.694 & 2.360 \\
All respondents & 4.164 & 2.231 \\
\hline Notes: European Social Survey, 2012 $(\mathrm{n}=51,547)$ &
\end{tabular}


Table 4. Explaining Political Trust

\begin{tabular}{|c|c|c|c|c|c|c|}
\hline & Model I & Model II & Model III & Model IV & Model V & Model VI \\
\hline $\begin{array}{l}\text { Democratic Ideals (ref: Medium) } \\
\text { Low ideals }\end{array}$ & $\begin{array}{l}-0.050 \\
(0.033)\end{array}$ & $\begin{array}{l}-0.050 \\
(0.033)\end{array}$ & $\begin{array}{l}-0.050 \\
(0.033)\end{array}$ & $\begin{array}{l}-0.050 \\
(0.033)\end{array}$ & $\begin{array}{l}-0.050 \\
(0.033)\end{array}$ & $\begin{array}{l}0.929 * * * \\
(0.145)\end{array}$ \\
\hline High ideals & $\begin{array}{l}-0.273^{* * *} \\
(0.025)\end{array}$ & $\begin{array}{l}-0.272^{* * *} \\
(0.025)\end{array}$ & $\begin{array}{l}-0.273^{\text {**** }} \\
(0.025)\end{array}$ & $\begin{array}{l}-0.272^{* * *} \\
(0.025)\end{array}$ & $\begin{array}{l}-0.272^{* * *} \\
(0.025)\end{array}$ & $\begin{array}{l}-1.054 * * * \\
(0.139)\end{array}$ \\
\hline Political rights & $\begin{array}{l}0.114^{* * *} \\
(0.027)\end{array}$ & $\begin{array}{l}0.114^{* * *} \\
(0.027)\end{array}$ & $\begin{array}{l}0.114^{* * *} \\
(0.027)\end{array}$ & $\begin{array}{l}0.114^{* * *} \\
(0.027)\end{array}$ & $\begin{array}{l}0.114^{* * *} \\
(0.027)\end{array}$ & $\begin{array}{l}-0.602 * * \\
(0.187)\end{array}$ \\
\hline Social rights & $\begin{array}{l}-0.158^{* *} \\
(0.026)\end{array}$ & $\begin{array}{l}-0.158^{* * *} \\
(0.026)\end{array}$ & $\begin{array}{l}-0.158^{\text {**** }} \\
(0.026)\end{array}$ & $\begin{array}{l}-0.158^{* * *} \\
(0.026)\end{array}$ & $\begin{array}{l}-0.158^{* * *} \\
(0.026)\end{array}$ & $\begin{array}{l}-0.326 \\
(0.210)\end{array}$ \\
\hline Age & $\begin{array}{l}-0.043^{* * *} \\
(0.003)\end{array}$ & $\begin{array}{l}-0.043^{* * * *} \\
(0.003)\end{array}$ & $\begin{array}{l}-0.043^{* * * *} \\
(0.003)\end{array}$ & $\begin{array}{l}-0.043^{* * *} \\
(0.003)\end{array}$ & $\begin{array}{l}-0.043^{* * *} \\
(0.003)\end{array}$ & $\begin{array}{l}-0.044 * * * \\
(0.003)\end{array}$ \\
\hline Age $^{2}$ & $\begin{array}{l}0.000^{* * *} \\
(0.000)\end{array}$ & $\begin{array}{l}0.000^{* * * *} \\
(0.000)\end{array}$ & $\begin{array}{l}0.000^{* * * *} \\
(0.000)\end{array}$ & $\begin{array}{l}0.000^{* * *} \\
(0.000)\end{array}$ & $\begin{array}{l}0.000^{* * *} \\
(0.000)\end{array}$ & $\begin{array}{l}0.000 * * * \\
(0.000)\end{array}$ \\
\hline Sex $(1=$ female $)$ & $\begin{array}{l}-0.037^{*} \\
(0.018)\end{array}$ & $\begin{array}{l}-0.037^{*} \\
(0.018)\end{array}$ & $\begin{array}{l}-0.037^{*} \\
(0.018)\end{array}$ & $\begin{array}{l}-0.037^{*} \\
(0.018)\end{array}$ & $\begin{array}{l}-0.037^{*} \\
(0.018)\end{array}$ & $\begin{array}{l}-0.041^{*} \\
(0.018)\end{array}$ \\
\hline Mid & $\begin{array}{l}0.087^{* * *} \\
(0.024)\end{array}$ & $\begin{array}{l}0.087^{* * *} \\
(0.024)\end{array}$ & $\begin{array}{l}0.088^{* * *} \\
(0.024)\end{array}$ & $\begin{array}{l}0.087^{* * *} \\
(0.024)\end{array}$ & $\begin{array}{l}0.087^{* * * *} \\
(0.024)\end{array}$ & $\begin{array}{l}0.079 * * \\
(0.024)\end{array}$ \\
\hline High & $\begin{array}{l}0.439^{* * *} \\
(0.025)\end{array}$ & $\begin{array}{l}0.439^{* * *} \\
(0.025)\end{array}$ & $\begin{array}{l}0.440^{* * * *} \\
(0.025)\end{array}$ & $\begin{array}{l}0.439^{* * *} \\
(0.025)\end{array}$ & $\begin{array}{l}0.440^{* * * *} \\
(0.025)\end{array}$ & $\begin{array}{l}0.420 * * * \\
(0.025)\end{array}$ \\
\hline Left-right & $\begin{array}{l}0.077^{* * *} \\
(0.004)\end{array}$ & $\begin{array}{l}0.077^{* * * *} \\
(0.004)\end{array}$ & $\begin{array}{l}0.077^{* * * *} \\
(0.004)\end{array}$ & $\begin{array}{l}0.077^{* * * *} \\
(0.004)\end{array}$ & $\begin{array}{l}0.077^{* * * *} \\
(0.004)\end{array}$ & $\begin{array}{l}0.079 * * * \\
(0.004)\end{array}$ \\
\hline $\begin{array}{l}\text { GDP/ cap } \\
\text { (1000 USD) } \\
\text { Established democracy } \\
\text { 'Weak' democracy } \\
\text { Good governance } \\
\text { (index) } \\
\text { Interactions } \\
\text { Good governance * Low expec. } \\
\text { Good governance *High expec. } \\
\text { Good governance *Political rights } \\
\text { Good governance *Social rights }\end{array}$ & & $\begin{array}{l}0.075^{* * *} \\
(0.008)\end{array}$ & $\begin{array}{l}1.522^{* * * *} \\
(0.314)\end{array}$ & $\begin{array}{l}-1.576^{* *} \\
(0.528)\end{array}$ & $\begin{array}{l}0.046^{* * * *} \\
(0.006)\end{array}$ & $\begin{array}{l}0.043 * * * \\
(0.006) \\
\\
-0.013 * * * \\
(0.002) \\
0.010 * * * \\
(0.001) \\
0.009 * * * \\
(0.002) \\
0.002 \\
(0.001)\end{array}$ \\
\hline $\begin{array}{l}\text { Constant } \\
\sigma_{u 0}^{2} \\
\sigma_{\text {Democratic ideals }}^{2}\end{array}$ & $\begin{array}{l}2.277^{* * *} \\
(0.290) \\
0.656^{* * *} \\
(0.087)\end{array}$ & $\begin{array}{l}1.154^{*} \\
(0.492) \\
0.537 * * * \\
(0.071)\end{array}$ & $\begin{array}{l}4.876^{* * * *} \\
(0.206) \\
0.625^{* * *} \\
(0.083)\end{array}$ & $\begin{array}{l}2.277^{* * *} \\
(0.290) \\
0.485^{* * *} \\
(0.064)\end{array}$ & $\begin{array}{l}3.765^{* * *} \\
(0.249) \\
0.656^{* * *} \\
(0.087)\end{array}$ & $\begin{array}{l}1.429^{* *} \\
(0.482) \\
0.635^{* * *} \\
(0.085) \\
0.059^{* * *} \\
(0.010)\end{array}$ \\
\hline Intra-class correlation & 0.2750 & 0.08926 & 0.1730 & 0.2248 & 0.1153 & 0.1104 \\
\hline
\end{tabular}

Note: Entries are results of a multilevel regression. Standard errors in parentheses. ${ }^{*} p<0.05,{ }^{* * *} p<0.01,{ }^{* * * *} p<0.001$. Source: ESS, $2012 \mathrm{~N}=43,277$ within 29 countries. Baseline model intra-class correlation: 0.28. The slope of 'democratic ideals' varies significantly over the countries $\left(\sigma_{\text {Democratic ideals }}^{2}=0.066\right.$ with SE 0.011$)$. 
Figure 1. Democratic Ideals Held by Five Groups

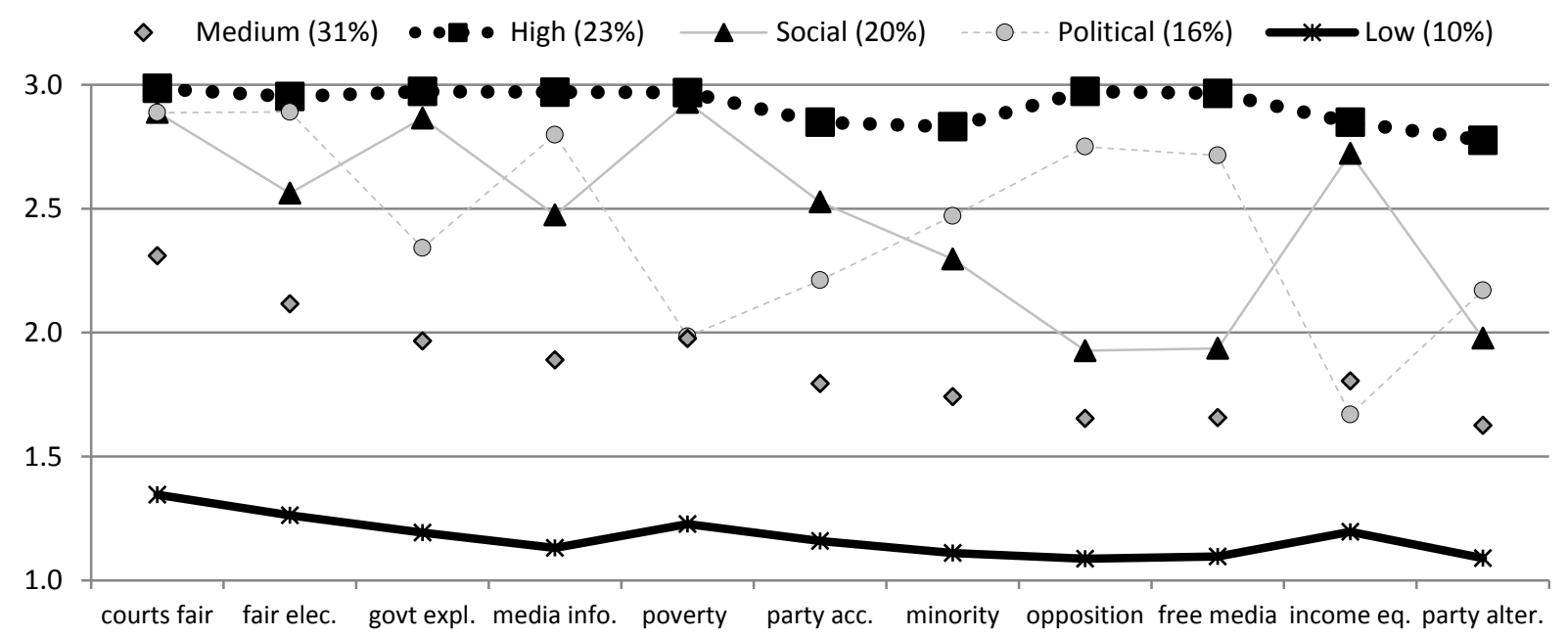

Notes: European Social Survey, 2012 ( $\mathrm{n}=54,673)$. Latent class analysis conditional probabilities for optimal partial equivalence model that includes country covariate and applies design weight for all cases ${ }^{9}$. The y-axis plots the conditional probabilities that members of a latent class will consider the indicators on the $\mathrm{x}$-axis to be important aspects of democracy. Indicators on the $\mathrm{x}$-axis are organized from left to right by decreasing means in the pooled dataset. Findings based on 3-point coding of the original 11-category democratic ideal items: 0-7 recoded as 1; 89 recoded as 2; 10 recoded as $3 .{ }^{10}$ See the online appendix for further documentation of model choice and measurement equivalence tests. 
Figure 2. Marginal Effect of Expectations and Governance on Political Trust (High and Low Groups)

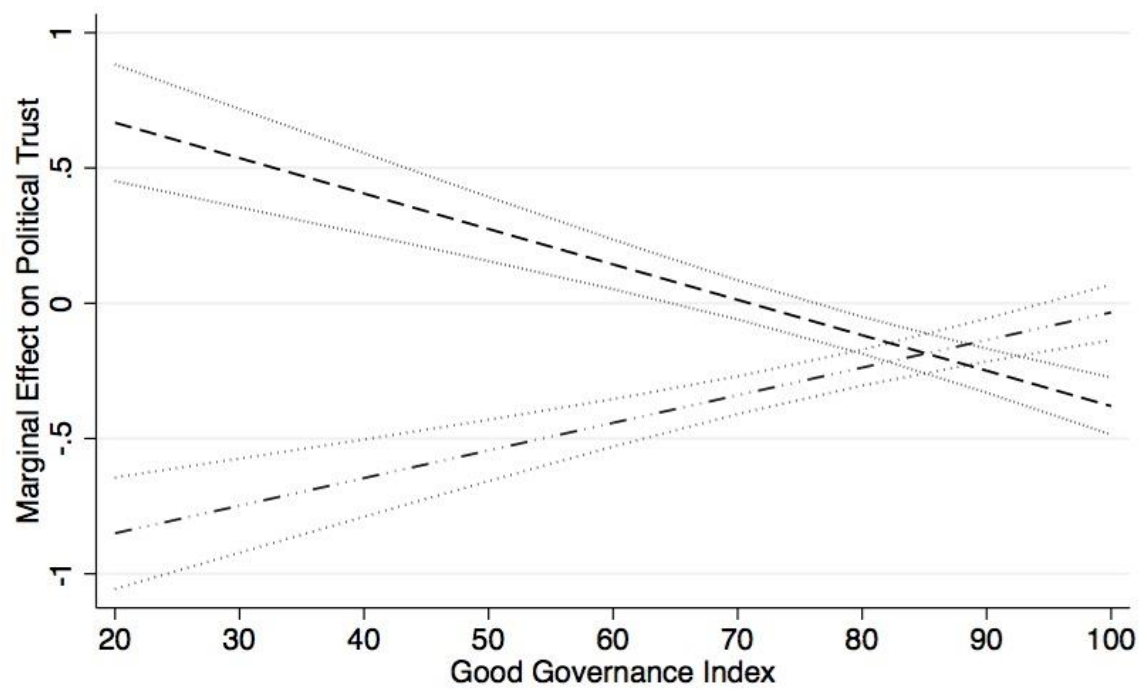

Low expectations group $\quad-\cdots-\cdots-$ High expectations group

Figure 3. Marginal Effect of Expectations and Governance on Political Trust (Social and Political Groups)

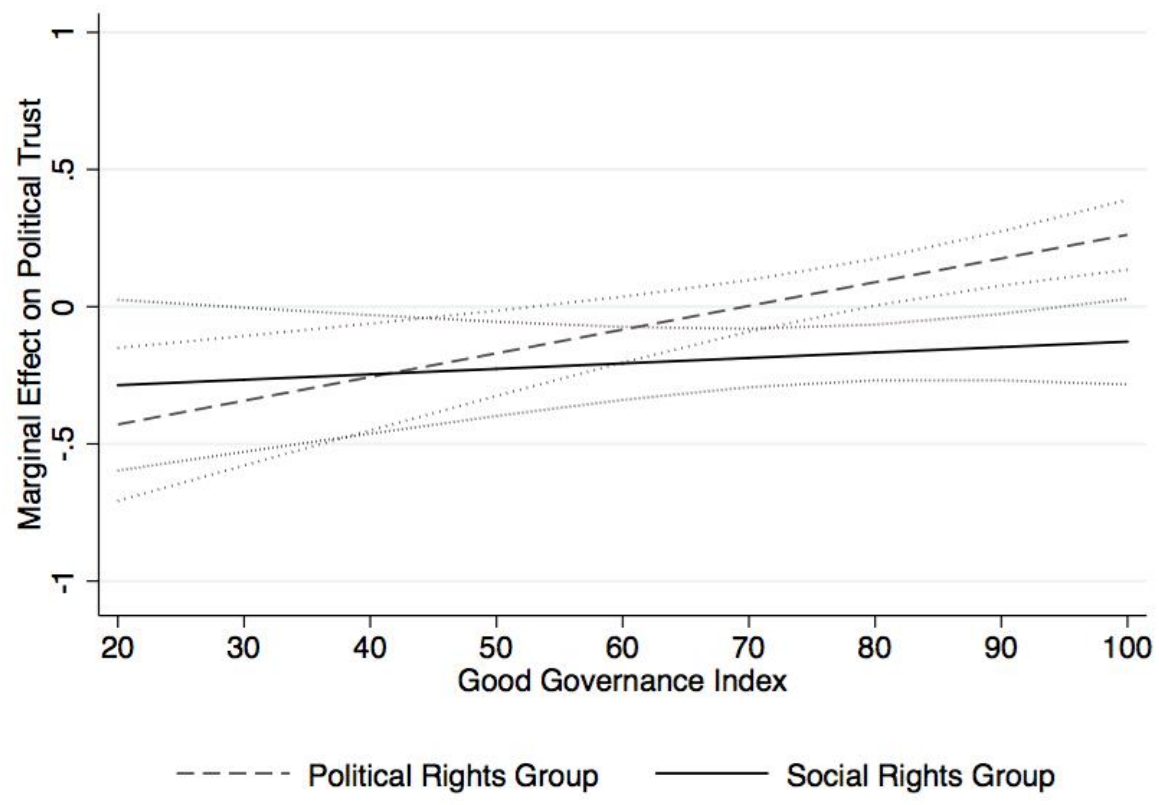


A3. Descriptive statistics multilevel analysis

\begin{tabular}{lccccc} 
Variables & N & Mean & SD & Min & Max \\
\hline Individual level variables & & & & & \\
Political trust & 43,277 & 4.363 & 2.171 & 0 & 10 \\
Expectations & & & & & \\
$\quad$ Low expectations group & 43,277 & 0.099 & 0.299 & 0 & 1 \\
$\quad$ Median expectation group (ref) & 43,277 & 0.309 & 0.462 & 0 & 1 \\
$\quad$ High expectations group & 43,277 & 0.227 & 0.419 & 0 & 1 \\
Political rights group & 43,277 & 0.171 & 0.376 & 0 & 1 \\
Social rights group & 43,277 & 0.195 & 0.396 & 0 & 1 \\
Age & 43,277 & 48.48 & 18.110 & 15 & 103 \\
Sex & 43,277 & 0.480 & 0.500 & 0 & 1 \\
Education & & & & & \\
$\quad$ Lowest & 43,277 & 0.260 & 0.438 & & \\
Middle & 43,277 & 0.368 & 0.482 & 0 & 1 \\
$\quad$ Highest & 43,277 & 0.373 & 0.483 & 0 & 1 \\
Ideology (Left-right) & 43,277 & 5.225 & 2.325 & 0 & 1 \\
Country-level variables & & & & & \\
GDP/cap in 1000 USD & 43,277 & 33.253 & 12.345 & 8.223 & 61.896 \\
Established democracy & 43,277 & 0.625 & 0.484 & 0 & 1 \\
Weak democracy & 43,277 & 0.102 & 0.303 & 0 & 1 \\
Good Governance index (sum-scale & 73,277 & 78.423 & 18.526 & 27.629 & 98.349 \\
values on criteria) & 43,25 &
\end{tabular}




\section{Endnotes}

1. It would be more correct to label this as a scale on 'trust in political institutions'. In line with the literature, and for the sake of clarity, we will abbreviate this to 'political trust' (Marien, 2011). This study demonstrates that this scale is cross-culturally equivalent. For the ESS too, the analysis revealed a strong consistent factor, not just for the entire ESS 2012 sample, but also within every participating country separately (see online appendix).

2 . The choice of eight as a cut off criteria and a period of 30 years might be seen as arbitrary. However, the classification of countries is similar to previous studies that included a variable for 'established democracy'. We have also tried different operationalisations varying the cutoff number as well as the period which led to similar results. Including the years of democracy as a continuous variable in the model does not change the results.

${ }^{3}$. Another commonly used country-level determinant of political trust is economic inequality (Zmerli \& Castillo 2015). We have not included this variable in the analysis as there is no comparable data on economic inequality for the 29 countries we study. Including economic inequality as a control variable would lead to a decrease in the number of country level observations to 22 . As a result the significance tests and the construction of intervals would be based on a rather small number of observations. Additional analyses on these 22 countries, however, shows a negative but insignificant effect of the GINI variable on political trust ( $\mathrm{p}$ value $=0.057$ ). The findings remain robust except for the effect of the 'low ideals'-group which becomes significant showing that the 'lower ideals'- group has a significantly lower level of trust than the 'medium ideals'-group. This change is driven by the smaller subset of data rather than the inclusion of GINI as a control variable and this finding does not contradict our overall results.

${ }^{4}$. In a separate analysis, the reported findings were confirmed by a fixed effects analysis, and by 29 separate analyses on every country in the dataset (see online appendix).

5 . These models are conducted on a sample of 43,277 observations. The ideology variable has a particularly large number of missing values $(8,216$ or $15 \%$ of the observations), but additional analyses excluding this variable led to similar results.

${ }^{6}$. In an additional analysis we also tested for non-linear interaction effects, but this did not improve the explained variance of the models (see online appendix).

7 . It has to be noted that we also controlled for the impact of potential outliers, and none of the results appear to be driven by any of the exceptional cases (see online appendix).

${ }^{8}$. As an additional test, we investigated whether it is indeed the distance between expectations and evaluations that affects political trust levels. Therefore, we used an additional battery of questions in the European Social Survey that asked respondents to evaluate their national political system on the same criteria that we use to investigate their democratic expectations. The question was: 'please tell me to what extent you think each of the following statements applies in [country]. 0 means you think the statement does not apply at all and 10 means you think it applies completely'. We constructed a 'distance' variable by subtracting a general expectations scale - in which all expectations scores were added - from a general evaluation scale in which all evaluations scores were added. We also created a second 'distance' variable by subtracting the respondent's evaluation from the respondent's expectation for every criterion seperately and adding these distances into one sumscale. Both operationalisation of distance led to the same results: a large distance between one's expectation and evaluation is associated with lower levels of political trust (controlling for all other variables in the model). Hence, this additional test confirms the expectation that high expectations can be associated with low levels of political trust. 
9 . The reported model includes all cases in the data, including those with missing data on the battery of questions regarding democratic ideals. The proportion of missing data on these indicators is low, ranging from 2 to $4 \%$ on each of the democratic ideals indicators, and the proportion of missing values on these indicators are evenly distributed throughout the countries in the study. We conducted two alternate analyses to test whether the findings would be affected by item non-response: (a) Conducting a listwise deletion of all cases that are missing data on any of the 11 democracy indicators, thereby analyzing the remaining $89.27 \%$ of the research population (b) Retaining cases that have missing data on only one indicator in the democratic ideals battery, thereby analyzing $94.61 \%$ of the research population (and excluding the $5.34 \%$ of cases that have missing data on 2 or more democratic ideals items). Analyses based on these alternate codings of missing data yielded the same substantive findings as those reported in the article.

${ }^{10}$. The advantage of recoding the original 11-category items into more parsimonious categories for the latent class analysis of these data is to avoid the problem of sparse data in analyzing categorical variables (Agresti, 2007). As evident in the presentation of the indicator means in Table 1, the variables in this battery are highly skewed toward the high end of the 11-point scale, so use of the original 11-category items creates a computational problem of sparse data. Relatedly, the more parsimonious coding enables the computationally intensive task of performing a definitive test of measurement equivalence across countries. In addition to the 3point recode findings reported in this article, we also performed robustness tests to investigate whether the findings were affected by using alternate codings, including: the original 11category response items; dichotomous cutoffs at $6,7,8,9,10$, as well as the mean or median of each variable; an alternate 3 -point coding $(0-8=1,9=2,10=3)$ and a 4-point coding $(0-7=1$, $8=2,9=3,10=4)$. These tests all yielded similar substantive results as those reported in the article. 